\title{
New Innovations: Therapies for Genetic Conditions
}

\author{
Farrah Rajabi · Jonathan D. Picker
}

Published online: 24 June 2014

(C) Springer Science + Business Media New York 2014

\begin{abstract}
New, mechanistic understanding of genetic disease is prompting the rapid advancement of treatments for these diseases. Treatment strategies for monogenic hereditary disorders and complex genetic disorders are evolving with novel uses of traditional medications, targeted therapies for biochemical deficiencies including enzyme replacement, and pathology-targeted pharmacologic approaches to enhance normal function. There is also tangible progress in the development of nucleic acidderived therapies, utilizing both DNA and RNA to modify gene expression and to correct a genetic disease process. Technologies that use antisense oligonucleotides, RNA interference, gene transfer, and stem cell transplantation are resulting in promising treatment breakthroughs. Though serious challenges remain in the safe and successful implementation of these technologies in clinical practice, the exciting prospect of treatment for previously untreatable genetic conditions is now within sight, providing hope for both patients and providers. Current options and evolving therapies are reviewed for the broad category of genetic disease.
\end{abstract}

F. Rajabi · J. D. Picker $(\square)$

Division of Genetics, Boston Children's Hospital, 300

Longwood Ave, Hunnewell 544, Boston, MA 02115, USA

e-mail: Jonathan.Picker@childrens.harvard.edu

J. D. Picker

Department of Child and Adolescent Psychiatry, Boston

Children's Hospital, Boston, MA, USA

J. D. Picker

Department of Pediatrics, Harvard Medical School, Boston, MA, USA
Keywords Genetic diseases - Genetic therapy: methods . Genetic therapy: trends - Genetics · Medical · Humans

\section{Introduction}

A new era in medical genetics is beginning. Since its inception, the field of genetics has focused on diagnosis, testing, and counseling. With few treatment options available for many disorders, there was little choice but to phenotype and characterize. However, as the underlying pathology of conditions becomes better understood, options for disease-specific treatments emerge, tailored either to the underlying genetic defect or to the consequences thereof. This is not a new concept; indeed, one of the most effective disorder-specific treatment strategies was first proposed in 1953 for phenylketonuria (PKU): the low-phenylalanine diet [1]. However, as the mechanistic understanding of disease at the molecular level has advanced, even disorders such as PKU with established treatments have experienced advances in treatment options $[2,3]$.

The focus of many trials has shifted away from the supportive management of symptoms, and instead on to new therapies targeting the underlying defects that result from genetic mutations. These therapies, whether pharmacologic or genetic, include the replacement of defective proteins, the improvement of protein function, or the diminishment of adverse consequences downstream of a defect [4]. However, challenges remain, particularly in the safe manipulation of gene expression. It is now 15 years since complications from the viral vector used in a transgenic trial led to the tragic death of Mr. Jesse Gelsinger [57]. This event and others prompted the research community to re-evaluate gene therapy and to look for alternatives. 
The result is a rich variety of approaches, both traditional and novel, to tackle varied genetic pathologies.

Therapeutic strategies range from the novel use of previously approved medications, to biochemically targeted therapies. More excitingly, there has also been tangible progress in the development of corrective therapies, involving both DNA and RNA to overwrite genetic disease processes. All of these new treatment approaches show both promise and challenges. We will begin with the repurposing of existing therapeutic options, before exploring compensatory therapies, nucleic acid-derived therapies, and possibilities for the future.

\section{Traditional Medical Therapies with New Uses}

As functional studies determine the biologic and molecular basis of rare diseases, existing medications are finding novel uses in a targeted-disease approach. Combining pharmacologic understanding of specific drugs to candidate pathologies provides an opportunity to capitalize on already approved medications. This allows for a rapid deployment, not possible for new agents that must go through the protracted trial process. Numerous examples demonstrate the promise of this utilitarian approach.

One example is Marfan syndrome, a connective tissue disorder with significant mortality related to cardiovascular disease including aortic root dilation, dissection, and rupture. Transforming growth factor $\beta$ (TGF- $\beta$ ) recently emerged as a potential mediator in the pathogenesis of these cardiovascular manifestations [8]. Losartan, an angiotensin II receptor blocker often used for hypertension, reduces TGF- $\beta$ activity and leads to a normalization of aortic root growth and architecture in mouse models [9]. Due to this dramatic protective result, clinical trials are nearing completion comparing cardiovascular outcomes in subjects receiving losartan to those treated with atenolol, the standard drug of choice for reducing hemodynamic stress on the aortic wall $[10,11]$.

Genetic causes of intellectual disability (ID) are also candidates for treatment with repurposed medications. The antibiotic minocycline is being used in fragile $\mathrm{X}$, the most common inherited genetic cause of ID. Anecdotal reports of cognitive and behavioral benefits to individuals with fragile $\mathrm{X}$ taking minocycline for acne led researchers to investigate possible mechanisms [12]. The metalloproteinase inhibitor role of minocycline as a secondary inhibitor of the mGluR5 receptor (discussed further in the "Targeted Therapies to Compensate for Metabolic or Biochemical Disequilibrium" section, below) provided a putative mechanism of action for this drug, separate from its established antibiotic function. Minocycline has since demonstrated some efficacy for treatment of fragile $\mathrm{X}$ in a double blind study $[12,13 \bullet]$. Similarly, in Down syndrome, the commonest genetic cause of ID, several medications are under investigation. Vitamin $\mathrm{E}$ has a suggested utility in Alzheimer's disease, and a clinical trial is currently underway studying whether it slows the cognitive decline of older adults with Down syndrome [14, 15]. Memantine, a glutamine antagonist also used in Alzheimer's disease, may provide limited cognitive improvement in verbal memory [16]. Lithium and baclofen are also under investigation, having been shown to improve cognitive performance in a Down syndrome mouse model [17-19].

Aminoglycoside antibiotics provide a novel approach for many genetic disorders. Streptomycin and gentamicin bind to rRNA and allow low-frequency read-through of premature stop codons, resulting in translational "skipping" over mutant stop codons [20, 21]. Cystic fibrosis is caused by mutations in the gene $C T F R$ which acts as a chloride channel, and approximately $10 \%$ of mutations in cystic fibrosis are caused by premature stop codons. Studies on nonsense-mediated cystic fibrosis have indicated that high dose gentamicin can amplify specific protein synthesis from less than $1 \%$ to up to $5 \%$ of normal levels [22, 23]. Potential benefit has also been shown in Hurler syndrome; a lysosomal storage disorder caused by deficiency in the $\alpha$-L-iduronidase enzyme with severe manifestations including mental retardation, hydrocephalus, physical disability, and hepatosplenomegaly. Preclinical fibroblast cell studies in Hurler syndrome have shown that gentamycin can induce the read-through of premature stop codons, resulting in enzyme activity that reduces substrate storage [24, 25]. However, the clinical benefit of gentamicin is limited, since it requires very high concentrations to be useful, and comes with the associated risk of severe side effects [26, 27]. These limitations have prompted investigation into the development of other compounds with a similar action but without the prohibitive side effects (discussed further in the "Gene Targeted Therapies" section below).

\section{Targeted Therapies to Compensate for Metabolic or Biochemical Disequilibrium}

In terms of established treatments, therapies involving dietary manipulations that alter the levels of deficient or excessive metabolites are perhaps the oldest genetic treatment options; as noted above for PKU, they can be transformative. Novel pharmacologic interventions in use or in development can alter or re-distribute metabolites, replace deficient enzymes, alter enzyme and channel activity, or inhibit pathogenic molecules, thereby restoring metabolic equilibrium. 


\section{Protein Replacement}

A milestone in the treatment of lysosomal storage disorders occurred with the introduction of enzyme replacement therapy (ERT). This was originally proposed in the 1960s for Gaucher's disease, the most prevalent lysosomal storage disorder caused by deficiency of the enzyme glucocerebrosidase [28]. Gaucher's disease results in glucosylceramide accumulation in various organs but particularly liver, spleen, bone marrow, and brain and results in an evolving morbidity, often with early death. The first successful ERT was developed for Gaucher disease, and was approved by the US Food and Drug Administration (FDA) in 1991 [29-31]. ERT is now available for Fabry disease, mucopolysaccharidosis (MPS) type I (Hurler syndrome), MPS type II (Hunter syndrome), MPS VI, and Pompe disease [27, 31]. Treatment of MPS type IVA (Moriquio A syndrome) with elosulfase alfa was FDA approved in February 2014 [32]. Other ERTs are in clinical trials, including treatment for Niemann-Pick disease type B [33]. However, a major limitation to ERT is limited access across the blood-brain barrier, to which intrathecal injections may be a solution. ERT has profoundly changed the outcome potential of lysosomal storage diseases; however, bone, cartilage, heart valve, and brain manifestations remain especially resistant to correction. Additionally, the monetary cost of ERT remains high [27].

\section{Enhancement of Normal Activity}

Molecular chaperones are small proteins that naturally act to stabilize unfolded proteins for cellular translocation, to assist in correct protein folding, and to assist in elimination of damaged and denatured proteins [27]. Protein function can be enhanced by the induction of natural chaperones or the administration of exogenous pharmacological chaperones, which can locate and rescue misfolded proteins, unstable mutant enzymes, or mistargeted proteins. Chemical chaperones are used to correct protein conformational defects, including the substrate analog deoxygalactonojirimycin for Fabry disease, $N$-(n-nonyl)deoxynojirimycin for common Gaucher mutation N370S, and galactonorjirimycin derivatives in GM1 gangliosidosis [34, 35]. These therapies offer potential for use in neurodegenerative lysosomal disorders, since the small molecules may cross the blood-brain barrier [27].

The cytosolic HSP70 chaperone system is involved in the ion-channel degradation of misfolded proteins seen in cystic fibrosis and long QT syndrome [36]. This chaperone is an attractive target for therapy; it may be manipulated to allow for improved folding of the mutant protein, and therefore partial restoration of function. Ivacaftor is also a promising new treatment for cystic fibrosis. It is targeted to individuals with the G551D missense mutation in the
CFTR gene, found in approximately $4 \%$ of individuals affected by cystic fibrosis. The medication acts as a channel potentiator, increasing the time that the activated CFTR channels at the cell surface remain open. Clinical trials demonstrated improvements in lung function at 2 weeks that were sustained through 48 weeks [37••]. Ivacaftor was FDA approved in January 2012, and is now under investigation for use in other CFTR mutations.

Cofactors are inorganic molecules that support the function of enzymes and biologic processes and provide another way to increase enzyme and channel activity. Curcumin, a compound isolated from turmeric, can influence a variety of ion channels. It is well studied for its effects on CFTR, where it acts by rescuing localization, allowing escape from the endoplasmic reticulum and stimulating channel activity at the plasma membrane [38, 39]. PKU can be improved in some patients through the use of sapropterin dihydrochloride (BH4) [2, 3]. Clinically BH4 increased residual enzyme activity. This may be attributed to an improved stability of the enzyme by a chaperone effect, or compensation by saturation of a kinetic binding of cofactor. Treatment with $\mathrm{BH} 4$ and subsequent increased dietary tolerance has led to improved quality of life measures in pediatric patients [40]. Supplemental large neutral amino acids (LNAAs) have also been used in PKU, and allow for a more relaxed diet plan. High concentrations of LNAA compete with phenylalanine transport across the blood-brain barrier, decreasing the amount of phenylalanine in the brain [41].

\section{Inhibition of Pathogenic Molecules}

In addition to increasing enzymatic function, another way to lessen disease phenotypes is to block the creation of pathogenic molecules. Tuberous sclerosis (TS) is a multisystem disorder including neurologic symptoms such as seizures, ID and autism, and a predisposition to benign tumors amongst other symptoms. TS is caused by mutations which encode proteins that form a complex to inhibit activation of the protein mammalian target of rapamycin (mTOR) [42]. The protein mTOR regulates both mGluR5 and ERK, and has been identified as a potential target for treatment by different groups [43, 44]. Inhibitory treatments targeted at the mTOR pathway work to reestablish equilibrium. Several drugs targeting this pathway, including rapamycin and everolimus are now in clinical trial or development [45]. This pathway is notably involved with a number of disorders that share features of ID and autistic symptomatology [46-48]. There is hope that these drugs may have utility for these related disorders as well as possible application for the greater population affected by autism [49]. In addition to mTOR 
inhibition, other inhibitory treatments have been developed, e.g., for tyrosinemia, an inborn error of metabolism resulting in liver failure and hepatocellular cancer. (2-(2-Nitro-4-trifluoromethylbenzoyl)-1,3-cyclohexadione) treats tyrosinemia type I by inhibiting 4-hydroxyphenylpyruvate dioxygenase, an enzyme in the tyrosine degradation pathway that would otherwise result in the production of succinylacetone, the toxic metabolite responsible for symptoms [50].

A similar approach has been developed for lysosomal storage diseases. These disorders, caused by defects involved in glycosphingolipid degradation, lead to the buildup of accumulated glycosphingolipid substrates derived from glucosylceramide. One approach to reduce the biosynthesis of glucosylceramide is inhibition of glucosylceramide synthases [51, 52]. Inhibition of glucosylceramide synthase with miglustat ( $N$-butyldeoxynojirimycin) can be used to treat patients with Gaucher disease type 1 who cannot receive ERT. Improvements in visceromegaly and hematological abnormalities have been demonstrated albeit high dose ERT appears to be more efficacious [53]. These small molecules, able to cross the blood-brain barrier, may also be useful in Gaucher disease type 3, Niemann-Pick disease type C, and GM2 gangliosidosis [52]. Miglustat has been used in NiemannPick disease type $\mathrm{C}$, with promising results showing a stabilization or slowing of disease progression [54, 55].

Other monogenic diseases also benefit from this inhibitory approach. In fragile $\mathrm{X}$, the loss of the fragile $\mathrm{X}$ protein, FMRP, leads to aberrant neuronal dendritic development and abnormal signaling [56, 57]. Lack of FMRP leads to unimpeded mGluR5 activity, particularly impacting the gamma-aminobutyric acidergic (GABAergic) system [58-60]. As a result, GABAergic function and mGluR5 activity levels are promising targets for potential therapies. Specific mGluR5-specific antagonist trials have been carried out (involving the drugs AFQ056, RO4917523, and STX107), in hopes of replacing the inhibitor effect of the missing FMRP. Increasing GABAergic activity has been targeted with arbaclofen, a $\mathrm{GABA}_{\mathrm{B}}$ agonist and prodrug of baclofen, with initial results in humans suggesting improvement in social function [61]. Another example, in a very different disorder is in trial for Hutchinson-Gilford progeria syndrome (HGPS), a rare premature aging disorder. HGPS is caused by mutations in LMNA leading to accumulation of progerin, an aberrant form of the inner nuclear membrane protein lamin A [62]. Farnesylation is a crucial posttranslational processing step for protein intercalation into the inner nuclear membrane. This can be prevented with the use of farnesyltransferase inhibitors, such as lonafarnib, which is currently in phase 2 clinical trials as an oral treatment for HGPS [63, 64].
Of perhaps greater significance at a population level are protein inhibitory studies in Down syndrome. A potentially important therapeutic target in Down syndrome identified by immunohistopathology and mouse model studies is the DYRK1A gene, which is overexpressed in the disorder. DYRK1A has been associated with neurofibrillary tangles and splicing regulation, and is thought to be responsible for some of the pathology of the disorder [65]. Epigallocatechin gallate, a polyphenol derived from green tea, inhibits DYRK1A function and is currently under active investigation $[66,67]$.

\section{Gene-Targeted Therapies}

Drug therapy does show promise for resolving some downstream effects of genetic disorders; however, this approach remains a secondary response. In many cases, the use of medications will at best ameliorate the symptoms that result from a more complex process than is being targeted. To truly solve the problem of a genetic disease, it is necessary to treat at a genetic level, via activation, inactivation, or modification of the target genes.

\section{Increasing Gene Expression}

Globally, the hemoglobinopathies, such as sickle cell anemia and thalassemia, are genetic disorders that cause significant morbidity and mortality. Reactivation of fetal hemoglobin $(\mathrm{HbF})$ expression, which is otherwise turned off in the neonatal period, is an important therapeutic option. Experimental HbF-inducing agents are the subjects of clinical trials for both sickle cell anemia and thalassemia $[68,69]$. DNA methylation is involved in silencing of the gamma-globin $(\mathrm{HbF})$ gene. Inhibiting DNA methyltransferase using decitabine (5-aza-2'-deoxycytidine) results in DNA hypomethylation, and has been demonstrated to increase $\mathrm{HbF}$ levels in a small number of patients with sickle cell anemia [70]. Decitabine is also under investigation as a therapy for multiple malignancies, as it can reactivate tumor suppressor genes silenced by aberrant DNA methylation, a frequent event in all types of cancer [71]. Further directions in treatment for hemoglobin disorders are being developed after genome-wide association studies, and traditional linkage studies have identified $B C L 11 \mathrm{~A}$ as a potent silencer of $\mathrm{HbF}$ and $K L F 1$ as a transcription factor that activates BCL11A [72].

Though many of the syndromic genetic disorders are rare, collectively they affect a large number of individuals [73]. Nonsense mutations resulting in premature termination codons (PTCs) are thought to cause between 5 and $20 \%$ of genetic disorders [74, 75]. The small organic 
molecule PTC124 encourages the translation machinery to ignore PTCs without preventing it from reading real stop signals, using a mechanism that parallels that of aminoglycoside antibiotics. It is proposed that PTC124, which lacks the side effects of gentamycin, may be beneficial in a clinical setting [27, 76]. PTC124 has received particular attention for trials in cystic fibrosis and Duchenne muscular dystrophy (DMD) [74]. Theoretically, this mechanism could be applied to many other disorders caused by nonsense mutations resulting in premature stop codons [77, 78]. As new PTC-skipping compounds are developed, this avenue will continue to evolve, as is already being seen animal studies involving the aminoglycoside NB84 for example [79].

\section{Blocking Gene Expression}

Gene-blocking therapies are particularly effective in correcting abnormal gain-of-function mutations, in which the aberrant product of the mutation is more harmful than its absence. Gene-blocking can also be used to inhibit production of precursors in a disease-causing pathway. One way to achieve this is with antisense oligonucleotides (AONs), single-stranded DNA oligonucleotides complementary to mRNA transcripts, which can target the mRNA resulting from gain-of-function mutations. The AON binds to the abnormal mRNA, preventing its translation into a harmful protein. Alternatively, an oligonucleotide can be engineered to bind to the dsDNA containing the diseasecausing mutation, creating a triple helix that cannot be transcribed into mRNA. This method depends upon the oligonucleotide not being degraded prior to reaching it's target $[80,81]$. Gene-blocking therapies can also inhibit a pathway made harmful due to a loss-of-function mutation. Familial hypercholesterolemia is a genetic disorder that leads to premature coronary artery disease due to loss-offunction mutations in the low-density lipoprotein (LDL) receptor. Mipomersen is a modified AON designed to inhibit translation of the apolipoprotein B protein. Inhibition of apolipoprotein B synthesis by mipomersen effectively lowered LDL cholesterol concentrations in homozygous patients [82•]. Mipomersen was FDA approved for treatment of homozygous familial hypercholesterolemia in January 2013, and clinical trials are underway to evaluate its use in related disorders [83].

AON-mediated splicing modulation can also target premRNA to create exon skipping by splice-switching oligomers. This is achieved with AON complementary to regions of the pre-mRNA transcript relevant for targeting, allowing skipping over mutant stop codons that are present in the spliceform and restoration of the open reading frame [80, 81]. This type of exon skipping is a promising therapy for DMD, where loss of dystrophin results in progressive and severely disabling neuromuscular disease. In Becker's muscular dystrophy, a shortened but still functional dystrophin protein results in a less severe disease profile, suggesting that even partial replacement of the protein product may have practical benefits. Exon-skipping with AON improves both dystrophin expression and muscle strength in animal models, and clinical trials are currently underway using intramuscular injections of anti-sense oligoribonucleotides for the treatment of DMD [84-87]. This technology also has potential applications in spinal muscular atrophy, ataxia telangiectasia, and congenital disorders of glycosylation, amongst other conditions [80, 88].

MicroRNAs (miRNAs) are a class of small noncoding RNAs that bind to mRNA and regulate its translation. Unlike AONs, miRNAs do not necessarily target nucleic acid; therapeutic miRNAs can act at the ribosome to inhibit indiscriminate translation of mRNA moieties with potential clinical applications. In models of fragile $\mathrm{X}$, the use of miRNA to inhibit translation resulted in improved spine morphology [89]. The regulation of genes through miRNA manipulation is well demonstrated in research settings, and is being studied with interest for potential therapeutic applications.

RNA may also therapeutically modulate aberrant gene expression via RNA interference (RNAi). This is a naturally occurring intracellular mechanism triggered by the presence of double-stranded RNA (dsRNA), which results in the targeted destruction of mRNA and subsequent cessation of protein translation [90]. Because many viruses produce dsRNA, cells of all multicellular organisms recognize this as a form of alien RNA and use the enzyme dicer to digest it into small pieces. These pieces are then used as a template to direct the destruction of any single-stranded RNA with the same sequence as the double-stranded viral RNA [81, 90]. RNAi can be manipulated to result in knockdown of single or multiple genes, and can be expressed as miRNAs or as short hairpin RNAs (shRNA). Introducing a shRNA complementary to the mutant gene can be used to interfere with expression of the mutant allele, leaving the wild-type allele unaffected. Alternately, it can interfere with the expression of both alleles if used in conjunction with gene transfer of a functional gene copy which has been modified to be RNAi-resistant. Viral vectors can be used to introduce RNAi into cells, and have been used effectively in models for neurodegenerative diseases, including Huntington disease and spino-cerebellar ataxia [91].

\section{Gene Replacement Therapy}

While manipulating the effects of mutated genes can have great clinical utility, the ultimate therapeutic goal is the permanent repair of the affected genes. Internationally, 
over 1,800 gene therapy clinical trials have been approved, completed, or are underway [92], with the first successful treatment by gene therapy of X-linked severe combined immunodeficiency (SCID) in 2000 [93]. Following the hiatus to resolve safety issues exposed by the death of Jesse Gelsinger [6], work to completely overhaul deficient genes has continued, using different approaches in order to maximize efficacy while limiting potential toxicity.

\section{Transplantation Gene Therapy}

Somatic cell gene therapy can be carried out via transplantation, to introduce wild-type copies of a gene into patients requiring functional gene copies. These methods are well suited to the correction of a loss-of-function mutation resulting in a nonfunctional or missing gene product. Clinical gene therapy trials for monogenic diseases have been conducted, with some particularly promising published results for a variety of conditions, including: SCID, cystic fibrosis, ornithine transcarbamylase deficiency, hemophilia B, chronic granulomatous disease (CDG), epidermolysis bullosa, juvenile neuronal ceroid lipofuscinosis, Canavan disease, lipoprotein lipase, alpha-1 antitrypsin deficiency, Leber congenital amaurosis (LCA), and X-linked adrenoleukodystrophy [27, 92].

Whole liver transplantation has been used to correct functional enzymatic impairment in a number of metabolic disorders, including: urea cycle disorders, organic acidurias, homozygous familial hypercholesterolemia, and severe forms of glycogen storage disease [27]. Alternately, ABO blood group-compatible hepatocytes can be infused intraportally into the patient's liver, where a portion of the cells will engraft and replace the deficient metabolic function. Hepatocyte transplantation is less invasive than organ transplantation, and results in clinical improvement and partial correction of the metabolic abnormality in most cases; however, it requires immunosuppression similar to that given to whole-organ transplantation recipient [94].

Hematopoietic stem cell (HSC) transplantation with pluripotent stem cells is capable of reconstituting all blood lineages completely and permanently. SCID has been a primary target for HSC gene therapy, since even a small number of engrafted marrow cells from an HLA-matched sibling can completely restore a patient's immune system. Ex vivo gene transfer can be used, but transduced cells will be out-competed unless a provided with a selective advantage, by the expression of a therapeutic gene (as used for SCID caused by adenosine deaminase deficiency, ADA), or by reducing the mass of untransduced cells by myeloablative chemotherapy. HSC transplantation has also been used to treat more than 20 inborn errors of metabolism, including: Hunter syndrome and other MPS disorders, X-linked adrenoleukodystrophy, metachromatic leukodystrophy, and globoid cell leukodystrophy [27, 95]. Currently, it is considered the only effective therapy for childhood cerebral X-linked adrenoleukodystrophy [96]. However, not all lysosomal storage diseases respond to HSC transplantation, and transplant-related morbidity must be considered. There are also several issues still to be resolved, especially concerning the safe and accurate direction and reprogramming of stem cell differentiation in the desired direction, and in a specific, and controllable manner [97].

A combination approach, using gene therapy applied to HSCs to overexpress lysosomal enzymes, augments the potential of HSC transplantation. Genetically modified bone marrow-derived cells that over-express lysosomal enzymes can migrate into the central nervous system and provide a transacting benefit to neighboring brain cells [98]. Umbilical cord blood (UCB) transplantation is another emerging technology [99]. Transplantation can be employed with UCB as a stem cell source within a month of diagnosis, which is now a successful treatment option for infants with Hurler syndrome and presymptomatic Krabbe disease [100, 101]. Additionally, engraftment rates for UCB are reportedly higher compared with other stem cell sources. Furthermore, adding enzyme replacement after transplantation has been associated with better cognitive outcomes in children with Hurler syndrome, highlighting the potential benefit of combining new therapeutic approaches [102]. Finally, pluripotent stem cells are not the only such cell type with clinical utility; corneal stem cells have also been used to regenerate the corneal epithelium $[103,104]$. There is also enormous potential for common disorders seen in the population, exemplified by promising studies of combined somatic cell reprogramming gene therapy in animal models of Parkinson's disease and sickle cell anemia $[105,106]$.

\section{Transductive Gene Therapy}

Transduction is the introduction of foreign DNA into a host cell via a viral vector. The foreign DNA can be used to replace a missing gene product by inserting a normal gene into somatic cells. However, there are many potential barriers to the introduction of foreign DNA. It is critical to ensure that the introduced gene targets the appropriate tissue and, once incorporated, is expressed appropriately. The gene is typically inserted, via heterologous recombination, whereby the gene is nonspecifically inserted into the genome and not at it's natural site. It is, therefore, not regulated in the same manner as the endogenous gene. Thus, there may be only transient and low-level expression, unable to yield a phenotypic effect. The cell may also methylate and inactivate the foreign DNA. There is also a potential for insertional mutagenesis with subsequent immune response [7, 81, 92, 107]. Gene therapy clinical 
trials to date have targeted numerous inherited monogenic diseases, though current trials are addressing treatment for cancer and cardiovascular disease as well.

The first successful transductive gene therapy trials used retroviral vectors; however, early trials in treatment of X-linked SCID demonstrated the adverse effects: after the retrovirus vector integrated near the $\mathrm{LMO} 2$ proto-oncogene promoter (insertional mutagenesis), it led to aberrant transcription and expression of $L M O 2$ and subsequent development of $\mathrm{T}$ cell leukemia [108]. Clinical gene therapy trials were put on hold after these events in 2008, and a worldwide effort was undertaken to improve vector safety. Currently, trials for both X-linked SCID and ADA related SCID (ADA-SCID) are underway using safer vectors [92, 109]. ADA-SCID cases thus treated with gene therapy have demonstrated reconstitution of immune function in the majority of cases, without adverse events related to the gene transfer technology. Use of retroviral vectors for treatment of a primary immunodeficiency CDG demonstrated initial success with lack of infections and improved quality of life after gene therapy. However, one of the patients involved in the initial clinical trial died from a severe bacterial infection as a result of the return of the CDG, later determined to be caused by silencing of the transgene from methylation of the viral promoter [92, 110, 111].

Several other viral vectors have been developed, involving lentiviral vectors, adenoviral vectors, and adenoassociated viral (AAV) vectors. Each has varying advantages and disadvantages. Difficulties include: transduction limited to dividing cells, short-term expression, low efficiency of transduction, acute toxicity, random integration, and insertional carcinogenesis $[4,81,111]$. Lentiviral vectors for gene therapy have been used for X-linked adrenoleukodystrophy, a fatal demyelinating disease of the central nervous system, with clinical benefit demonstrated in two patients [112]. AAV vectors have successfully targeted gene transfer to a small number of cells in the retina, liver, muscle, or lung, in multiple models. Treatment of LCA, a form of congenital blindness, using sub-retinal administration of recombinant AAV vectors expressing the gene has had promising results [113]. AAV-mediated liver gene transfer has been used successfully in animal models to treat several inborn errors of metabolism, including lysosomal storage disease, urea cycle disorders, and aminoacidopathies [111, 114].

Current clinical trials are examining the potential utility of gene therapy for treatment of hemophilia B and lipoprotein lipase deficiency in adults $[115,116]$. In both trials, only transient clinical benefit was observed, a result of the immune response directed against the vector constituents and cell-mediated destruction of the gene-corrected cells in the liver and muscle. Modulation of the immune system or transient immune suppression has been trialed in some protocols, and may be necessary to prevent unwanted immune responses.

\section{Future Therapies}

\section{Nonviral Vectors}

Given the risks inherent with the use of viral vectors, there is an understandable interest in gene therapy using nonviral vectors. The simplest non-viral gene delivery uses "naked" DNA injected directly into certain tissues, especially muscle tissue, and produces significant levels of gene expression [4, 111]. More popular is the non-viral systemic vector which uses cationic lipid/DNA complexes [92]. Non-viral vectors, however, lack the transfer efficiency of viruses, and most of the DNA inserts are degraded in the cytoplasm.

\section{Gene Repair}

Homologous recombination, whereby genetic material is inserted into the correct region on the genome, occurs naturally in mammalian cells, and in rare circumstances can lead to a spontaneous self-correction of disease by altering the pathogenic mutation [117-119]. Strategies based on AAV vectors or induction of DNA double-strand breaks has been used to increase the rate of homologous recombination for potential therapeutic use. Zinc-finger nucleases with a DNA-binding domain and a DNA-cleaving domain have also been used to induce homologous recombination. Precision is needed to ensure zinc-finger nucleases have minimal off-target DNA double-strand breaks, in order to reduce mutagenesis and chromosomal translocations [111, 120, 121].

\section{Conclusion}

As the technical barriers to the successful treatment of genetic disorders are being overcome, there are other factors that must be considered. In the internet age, patients and their families are more involved in the mechanism of trial creation and the approval process, and are able to advocate in increasingly influential ways. After a clinical trial for the drug arbaclofen was suddenly and unexpectedly closed due to a funding shortfall, parents started an online petition to congress and gathered support for the trial on social media [122]. The family of a boy affected by DMD recently submitted a 100,000 signature petition to the White House that urged the FDA to use an accelerated approval pathway for safe and effective therapies for 
DMD. As a result, the FDA released a detailed report outlining a potential accelerated path forward for those therapies $[123,124]$. These patients and their families are empowered by hope and optimism to push for the discovery of cures.

From a biological perspective, therapy may not be able to solve every problem in a practical and timely manner. Many genetic conditions cause pre-diagnostic fetal damage, and major congenital malformations remain a challenge for treatment [4]. Occasionally, these problems can be anticipated, if there is a known family history, or with carrier screening. Strategies for prenatal treatment of inherited and congenital disorders have been developed, including prenatal medical and surgical treatment, as with dexamethasone administration for congenital adrenal hyperplasia [4, 81]. However, many disorders still do not have identified causative genes, and for others the pathogenesis is not fully understood. The increased use of whole exome and whole genome sequencing will certainly lead to a better understanding of the contributory genes, but functional studies will still be needed to identify targets for treatment. Despite setbacks and difficulties seen with new treatment options, progress is being made. There is much optimism that these approaches will herald a new era in medicine, providing hope where it was not previously possible.

More information about new clinical trials and developments in genetic therapies is available via many sources, including ClinicalTrials.gov and www.gemcris.od.nih.gov.

Acknowledgments Our thanks to Katherine Pawlowski for her assistance with editing.

Disclosure F. Rajabi declares no conflicts of interest. J. D. Picker was a board member for Hoffman LaRoche and a consultant for Novartis.

Human and Animal Rights and Informed Consent This article does not contain any studies with human or animal subjects performed by any of the authors.

\section{References}

Papers of particular interest, published recently, have been highlighted as:

- Of importance

•- Of major importance

1. Bickel H, Gerrard J, Hickmans E. Influence of phenylalanine intake on phenylketonuria. Lancet. 1953;265:812-3.

2. Levy HL, Milanowski A, Chakrapani A, Cleary M, Lee P, Trefz FK, et al. Efficacy of sapropterin dihydrochloride (tetrahydrobiopterin, 6R-BH4) for reduction of phenylalanine concentration in patients with phenylketonuria: a phase III randomised placebo-controlled study. Lancet. 2007;370:504-10.
3. Blau N, van Spronsen FJ, Levy HL. Phenylketonuria. Lancet. 2010;376:1417-27.

4. Nussbaum RL, Mcinnes RR, Willard HF, Hamosh A. Chapter 13: the treatment of genetic disease. In: Thompson and Thompson genetics in medicine. 7th ed. Philadelphia, PA: W.B. Saunders; 2007. p. 393-418.

5. Raper SE, Yudkoff M, Chirmule N, Gao G-P, Nunes F, Haskal $\mathrm{ZJ}$, et al. A pilot study of in vivo liver-directed gene transfer with an adenoviral vector in partial ornithine transcarbamylase deficiency. Hum Gene Ther. 2002;13:163-75.

6. Stolberg SG. The biotech death of Jesse Gelsinger. NY Times Mag. 1999;136-140(28 Nov):149-50.

7. Wilson JM. Lessons learned from the gene therapy trial for ornithine transcarbamylase deficiency. Mol Genet Metab. 2009;96:151-7.

8. Neptune ER, Frischmeyer PA, Arking DE, Myers L, Bunton TE, Gayraud B, et al. Dysregulation of TGF-beta activation contributes to pathogenesis in Marfan syndrome. Nat Genet. 2003;33:407-11.

9. Habashi JP, Judge DP, Holm TM, Cohn RD, Loeys BL, Cooper TK, et al. Losartan, an AT1 antagonist, prevents aortic aneurysm in a mouse model of Marfan syndrome. Science. 2006;312:117-21.

10. Lacro RV, Dietz HC, Wruck LM, Bradley TJ, Colan SD, Devereux RB, et al. Rationale and design of a randomized clinical trial of beta-blocker therapy (atenolol) versus angiotensin II receptor blocker therapy (losartan) in individuals with Marfan syndrome. Am Heart J. 2007;154:624-31.

11. Radonic T, de Witte $\mathrm{P}$, Baars MJH, Zwinderman AH, Mulder BJM, Groenink M. Losartan therapy in adults with Marfan syndrome: study protocol of the multi-center randomized controlled COMPARE trial. Trials. 2010;11:3.

12. Siller SS, Broadie K. Matrix metalloproteinases and minocycline: therapeutic avenues for fragile X syndrome. Neural Plast. 2012;2012:124548.

13. - Leigh MJS, Nguyen DV, Mu Y, Winarni TI, Schneider A, Chechi T, et al. A randomized double-blind, placebo-controlled trial of minocycline in children and adolescents with fragile $\mathrm{X}$ syndrome. J Dev Behav Pediatr. 2013;34:147-55. This study demonstrated improved behavior in individuals with Fragile $X$ using minocycline.

14. Farina N, Isaac MGEKN, Clark AR, Rusted J, Tabet N. Vitamin E for Alzheimer's dementia and mild cognitive impairment. Cochrane Database Syst Rev. 2012;11:CD002854.

15. Li F-J, Shen L, Ji H-F. Dietary intakes of vitamin E, vitamin C, and $\beta$-carotene and risk of Alzheimer's disease: a meta-analysis. J Alzheimers Dis. 2012;31:253-8.

16. Boada R, Hutaff-Lee C, Schrader A, Weitzenkamp D, Benke TA, Goldson EJ, et al. Antagonism of NMDA receptors as a potential treatment for Down syndrome: a pilot randomized controlled trial. Transl Psychiatry Nat Publ Group. 2012;2:e141.

17. Contestabile A, Greco B, Ghezzi D, Tucci V, Benfenati F, Gasparini L. Lithium rescues synaptic plasticity and memory in Down syndrome mice. J Clin Investig. 2013;123:348-61.

18. Cramer N, Galdzicki Z. From abnormal hippocampal synaptic plasticity in Down syndrome mouse models to cognitive disability in Down syndrome. Neural Plast. 2012;2012:101542.

19. Kleschevnikov AM, Belichenko PV, Gall J, George L, Nosheny R, Maloney MT, et al. Increased efficiency of the GABAA and GA$\mathrm{BAB}$ receptor-mediated neurotransmission in the Ts65Dn mouse model of Down syndrome. Neurobiol Dis. 2012;45:683-91.

20. Davies J, Gilbert W, Gorini L. Streptomycin, suppression, and the code. Proc Natl Acad Sci USA. 1964;51:883-90.

21. Burke JF, Mogg AE. Suppression of a nonsense mutation in mammalian cells in vivo by the aminoglycoside antibiotics G-418 and paromomycin. Nucleic Acids Res. 1985;13:6265-72.

22. Kerem E. Pharmacologic therapy for stop mutations: how much CFTR activity is enough? Curr Opin Pulm Med. 2004;10: 547-52. 
23. Sermet-Gaudelus I, Renouil M, Fajac A, Bidou L, Parbaille B, Pierrot $\mathrm{S}$, et al. In vitro prediction of stop-codon suppression by intravenous gentamicin in patients with cystic fibrosis: a pilot study. BMC Med. 2007;5:5.

24. Keeling KM, Brooks DA, Hopwood JJ, Li P, Thompson JN, Bedwell DM. Gentamicin-mediated suppression of Hurler syndrome stop mutations restores a low level of alpha-L-iduronidase activity and reduces lysosomal glycosaminoglycan accumulation. Hum Mol Genet. 2001;10:291-9.

25. Brooks DA, Muller VJ, Hopwood JJ. Stop-codon read-through for patients affected by a lysosomal storage disorder. Trends Mol Med. 2006;12:367-73.

26. Zingman LV, Park S, Olson TM, Alekseev AE, Terzic A. Aminoglycoside-induced translational read-through in disease: overcoming nonsense mutations by pharmacogenetic therapy. Clin Pharmacol Ther. 2007;81:99-103.

27. Treacy EP. Treatment of genetic disease. In: Valle D, Beaudet A, Vogelstein B, Kinzler K, Antonarakis S, Ballabio A, et al., editors. OMMBID — online metabolic and molecular basis of inherited diseases. New York: McGraw-Hill; 2013.

28. Brady RO. The sphingolipidoses. N Engl J Med. 1966;275: 312-8.

29. Brady RO, Pentchev PG, Gal AE, Hibbert SR, Dekaban AS. Replacement therapy for inherited enzyme deficiency. Use of purified glucocerebrosidase in Gaucher's disease. N Engl J Med. 1974;291:989-93.

30. Barton NW, Brady RO, Dambrosia JM, Di Bisceglie AM, Doppelt SH, Hill SC, et al. Replacement therapy for inherited enzyme deficiency-macrophage-targeted glucocerebrosidase for Gaucher's disease. N Engl J Med. 1991;324:1464-70.

31. Brady RO. Enzyme replacement for lysosomal diseases. Annu Rev Med. 2006;57:283-96.

32. Sanford M, Lo JH. Elosulfase alfa: first global approval. Drugs. 2014;74(6):713-8.

33. Garnacho C, Dhami R, Simone E, Dziubla T, Leferovich J, Schuchman EH, et al. Delivery of acid sphingomyelinase in normal and Niemann-Pick disease mice using intercellular adhesion molecule-1-targeted polymer nanocarriers. J Pharmacol Exp Ther. 2008;325:400-8.

34. Fan J-Q. A contradictory treatment for lysosomal storage disorders: inhibitors enhance mutant enzyme activity. Trends Pharmacol Sci. 2003;24:355-60.

35. Suzuki Y. Beta-galactosidase deficiency: an approach to chaperone therapy. J Inherit Metab Dis. 2006;29:471-6.

36. Young JC. The role of the cytosolic HSP70 chaperone system in diseases caused by misfolding and aberrant trafficking of ion channels. Dis Model Mech. 2014;7:319-29.

37. •- Ramsey BW, Davies J, McElvaney NG, Tullis E, Bell SC, Dřevínek $\mathrm{P}$, et al. A CFTR potentiator in patients with cystic fibrosis and the G551D mutation. N Engl J Med. 2011;365:1663-72. This study evaluated the use of ivacaftor for individuals with cystic fibrosis and the G551D mutation demonstrating sustained improvement in lung function through 48 weeks.

38. Egan ME, Pearson M, Weiner SA, Rajendran V, Rubin D, Glöckner-Pagel J, et al. Curcumin, a major constituent of turmeric, corrects cystic fibrosis defects. Science. 2004;304:600-2.

39. Zhang X, Chen Q, Wang Y, Peng W, Cai H. Effects of curcumin on ion channels and transporters. Front Physiol. 2014;5:94.

40. Demirdas S, Maurice-Stam H, Boelen CCA, Hofstede FC, Janssen MCH, Langendonk JG, et al. Evaluation of quality of life in PKU before and after introducing tetrahydrobiopterin (BH4); a prospective multi-center cohort study. Mol Genet Metab Elsevier Inc. 2013;110(Suppl):S49-56.

41. Rocha JC, Martel F. Large neutral amino acids supplementation in phenylketonuric patients. J Inherit Metab Dis. 2009;32: 472-80.
42. Van Slegtenhorst M, de Hoogt R, Hermans C, Nellist M, Janssen $\mathrm{B}$, Verhoef $\mathrm{S}$, et al. Identification of the tuberous sclerosis gene TSC1 on chromosome 9q34. Science. 1997;277:805-8.

43. Inoki K, Li Y, Zhu T, Wu J, Guan K-L. TSC2 is phosphorylated and inhibited by Akt and suppresses mTOR signalling. Nat Cell Biol. 2002;4:648-57.

44. Tee AR, Fingar DC, Manning BD, Kwiatkowski DJ, Cantley LC, Blenis J. Tuberous sclerosis complex-1 and -2 gene products function together to inhibit mammalian target of rapamycin (mTOR)-mediated downstream signaling. Proc Natl Acad Sci USA. 2002;99:13571-6.

45. Sato A, Kasai S, Kobayashi T, Takamatsu Y, Hino O, Ikeda K, et al. Rapamycin reverses impaired social interaction in mouse models of tuberous sclerosis complex. Nat Commun Nat Publ Group. 2012;3:1292.

46. Schubbert S, Shannon K, Bollag G. Hyperactive Ras in developmental disorders and cancer. Nat Rev Cancer. 2007;7: 295-308.

47. Denayer E, Ahmed T, Brems H, Van Woerden G, Borgesius NZ, Callaerts-Vegh Z, et al. Spred1 is required for synaptic plasticity and hippocampus-dependent learning. J Neurosci. 2008;28: 14443-9.

48. Stiles BL. Phosphatase and tensin homologue deleted on chromosome 10: extending its PTENtacles. Int J Biochem Cell Biol. 2009;41:757-61.

49. Ebert DH, Greenberg ME. Activity-dependent neuronal signaling and autism spectrum disorder. Nature. 2013;493:327-37.

50. Holme E, Lindstedt S. Tyrosinaemia type I and NTBC (2-(2nitro-4-trifluoromethylbenzoyl)-1,3-cyclohexanedione). J Inherit Metab Dis. 1998;21:507-17.

51. Vunnam RR, Radin NS. Analogs of ceramide that inhibit glucocerebroside synthetase in mouse brain. Chem Phys Lipids. 1980;26:265-78.

52. Aerts JMFG, Hollak CEM, Boot RG, Groener JEM, Maas M. Substrate reduction therapy of glycosphingolipid storage disorders. J Inherit Metab Dis. 2006;29:449-56.

53. Cox TM, Aerts JMFG, Andria G, Beck M, Belmatoug N, Bembi $\mathrm{B}$, et al. The role of the iminosugar $N$-butyldeoxynojirimycin (miglustat) in the management of type I (non-neuronopathic) Gaucher disease: a position statement. J Inherit Metab Dis. 2003;26:513-26.

54. Patterson MC, Vecchio D, Prady H, Abel L, Wraith JE. Miglustat for treatment of Niemann-Pick C disease: a randomised controlled study. Lancet Neurol. 2007;6:765-72.

55. Ginocchio VM, D'Amico A, Bertini E, Ceravolo F, Dardis A, Verrigni D, et al. Efficacy of miglustat in Niemann-Pick C disease: a single centre experience. Mol Genet Metab Elsevier Inc. 2013;110:329-35.

56. Bagni C, Greenough WT. From mRNP trafficking to spine dysmorphogenesis: the roots of fragile $\mathrm{X}$ syndrome. Nat Rev Neurosci. 2005;6:376-87.

57. Bear MF. Therapeutic implications of the mGluR theory of fragile X mental retardation. Genes Brain Behav. 2005;4:393-8.

58. Comery TA, Harris JB, Willems PJ, Oostra BA, Irwin SA, Weiler IJ, et al. Abnormal dendritic spines in fragile X knockout mice: maturation and pruning deficits. Proc Natl Acad Sci USA. 1997;94:5401-4.

59. Niere F, Wilkerson JR, Huber KM. Evidence for a fragile $X$ mental retardation protein-mediated translational switch in metabotropic glutamate receptor-triggered Arc translation and long-term depression. J Neurosci. 2012;32:5924-36.

60. Rudelli RD, Brown WT, Wisniewski K, Jenkins EC, LaureKamionowska M, Connell F, et al. Adult fragile $\mathrm{X}$ syndrome. Acta Neuropathol. 1985;67:289-95.

61. Berry-Kravis EM, Hessl D, Rathmell B, Zarevics P, Cherubini M, Walton-Bowen K, et al. Effects of STX209 (arbaclofen) on 
neurobehavioral function in children and adults with fragile $\mathrm{X}$ syndrome: a randomized, controlled, phase 2 trial. Sci Transl Med. 2012;4:152ra127.

62. Merideth MA, Gordon LB, Clauss S, Sachdev V, Smith ACM, Perry MB, et al. Phenotype and course of Hutchinson-Gilford progeria syndrome. N Engl J Med. 2008;358:592-604.

63. Gordon LB, Kleinman ME, Miller DT, Neuberg DS, GiobbieHurder A, Gerhard-Herman M, et al. Clinical trial of a farnesyltransferase inhibitor in children with Hutchinson-Gilford progeria syndrome. Proc Natl Acad Sci USA. 2012;109: 16666-71.

64. Ullrich NJ, Kieran MW, Miller DT, Gordon LB, Cho Y-J, Silvera VM, et al. Neurologic features of Hutchinson-Gilford progeria syndrome after lonafarnib treatment. Neurology. 2013; 81:427-30.

65. Park J, Chung KC. New perspectives of Dyrk1a role in neurogenesis and neuropathologic features of Down syndrome. Exp Neurobiol. 2013;22:244-8.

66. Créau N. Molecular and cellular alterations in Down syndrome: toward the identification of targets for therapeutics. Neural Plast. 2012;2012:171639.

67. De la Torre R, Dierssen M. Therapeutic approaches in the improvement of cognitive performance in Down syndrome: past, present, and future. Prog Brain Res Elsevier Inc. 2012;197:1-14.

68. Atweh G, Fathallah H. Pharmacologic induction of fetal hemoglobin production. Hematol Oncol Clin N Am Elsevier Ltd. 2010;24:1131-44.

69. Olivieri NF, Saunthararajah Y, Thayalasuthan V, Kwiatkowski J, Ware RE, Kuypers FA, et al. A pilot study of subcutaneous decitabine in $\beta$-thalassemia intermedia. Blood. 2011;118: 2708-11.

70. Saunthararajah Y, Hillery CA, Lavelle D, Molokie R, Dorn L, Bressler L, et al. Effects of 5-aza-2'-deoxycytidine on fetal hemoglobin levels, red cell adhesion, and hematopoietic differentiation in patients with sickle cell disease. Blood. 2003; 102:3865-70.

71. Karahoca M, Momparler RL. Pharmacokinetic and pharmacodynamic analysis of 5-aza-2'-deoxycytidine (decitabine) in the design of its dose-schedule for cancer therapy. Clin Epigenet. 2013;5:3

72. Bauer DE, Orkin SH. Update on fetal hemoglobin gene regulation in hemoglobinopathies. Curr Opin Pediatr. 2011;23:1-8.

73. Jackson JM, Crider KS, Olney RS. Population-based surveillance for rare congenital and inherited disorders: models and challenges. Adv Exp Med Biol. 2010;686:133-50.

74. Peltz SW, Morsy M, Welch EM, Jacobson A. Ataluren as an agent for therapeutic nonsense suppression. Annu Rev Med. 2013;64:407-25.

75. Mort M, Ivanov D, Cooper DN, Chuzhanova NA. A metaanalysis of nonsense mutations causing human genetic disease. Hum Mutat. 2008;29:1037-47.

76. Welch EM, Barton ER, Zhuo J, Tomizawa Y, Friesen WJ, Trifillis P, et al. PTC124 targets genetic disorders caused by nonsense mutations. Nature. 2007;447:87-91.

77. Buck NE, Wood LR, Hamilton NJ, Bennett MJ, Peters HL. Treatment of a methylmalonyl-CoA mutase stopcodon mutation. Biochem Biophys Res Commun Elsevier Inc. 2012;427:753-7.

78. Popescu AC, Sidorova E, Zhang G, Eubanks JH. Aminoglycoside-mediated partial suppression of MECP2 nonsense mutations responsible for Rett syndrome in vitro. J Neurosci Res. 2010;88:2316-24.

79. Wang D, Belakhov V, Kandasamy J, Baasov T, Li S-C, Li Y-T, et al. The designer aminoglycoside NB84 significantly reduces glycosaminoglycan accumulation associated with MPS I-H in the Idua-W392X mouse. Mol Genet Metab Elsevier Inc. 2012;105:116-25.
80. Siva K, Covello G, Denti MA. Exon-skipping antisense oligonucleotides to correct missplicing in neurogenetic diseases. Nucleic Acid Ther. 2014;24:69-86.

81. Jorde LB, Carey JC, Bamshad MJ. Genetic testing and gene therapy. In: Jorde LB, Carey JC, Bamshad MJ, editors. Medical genetics. 4th ed. Philadelphia: Mosby; 2009. p. 258-83.

82. - Raal FJ, Santos RD, Blom DJ, Marais AD, Charng M-J, Cromwell WC, et al. Mipomersen, an apolipoprotein B synthesis inhibitor, for lowering of LDL cholesterol concentrations in patients with homozygous familial hypercholesterolaemia: a randomised, double-blind, placebo-controlled trial. Lancet Elsevier Ltd. 2010;375:998-1006. This study demonstrated a breakthrough therapy for familial hypercholesterolaemia.

83. Wong E, Goldberg T. Mipomersen (Kynamro): a novel antisense oligonucleotide inhibitor for the management of homozygous familial hypercholesterolemia. P T. 2014;39:119-22.

84. Cirak S, Arechavala-Gomeza V, Guglieri M, Feng L, Torelli S, Anthony K, et al. Exon skipping and dystrophin restoration in patients with Duchenne muscular dystrophy after systemic phosphorodiamidate morpholino oligomer treatment: an openlabel, phase 2, dose-escalation study. Lancet Elsevier Ltd. 2011;378:595-605.

85. Leung DG, Wagner KR. Therapeutic advances in muscular dystrophy. Ann Neurol. 2013;74:404-11.

86. Fletcher S, Honeyman K, Fall AM, Harding PL, Johnsen RD, Wilton SD. Dystrophin expression in the $\mathrm{mdx}$ mouse after localised and systemic administration of a morpholino antisense oligonucleotide. J Gene Med. 2006;8:207-16.

87. Yokota T, Lu Q-L, Partridge T, Kobayashi M, Nakamura A, Takeda S, et al. Efficacy of systemic morpholino exon-skipping in Duchenne dystrophy dogs. Ann Neurol. 2009;65:667-76.

88. Van Roon-Mom WMC, Aartsma-Rus A. Overview on applications of antisense-mediated exon skipping. Methods Mol Biol. 2012;867:79-96.

89. Darnell JC, Klann E. The translation of translational control by FMRP: therapeutic targets for FXS. Nat Neurosci Nat Publ Group. 2013;16:1530-6.

90. Martineau HM, Pyrah IT. Review of the application of RNA interference technology in the pharmaceutical industry. Toxicol Pathol. 2007;35:327-36.

91. Liu J, Pendergraff H, Narayanannair KJ, Lackey JG, Kuchimanchi S, Rajeev KG, et al. RNA duplexes with abasic substitutions are potent and allele-selective inhibitors of huntingtin and ataxin-3 expression. Nucleic Acids Res. 2013;41: 8788-801.

92. Ginn SL, Alexander IE, Edelstein ML, Abedi MR, Wixon J. Gene therapy clinical trials worldwide to 2012-an update. J Gene Med. 2013;15:65-77.

93. Cavazzana-Calvo M. Gene therapy of human severe combined immunodeficiency (SCID)-X1 disease. Science. 2000;288:669-72.

94. Dhawan A, Mitry RR, Hughes RD. Hepatocyte transplantation for liver-based metabolic disorders. J Inherit Metab Dis. 2006;29:431-5.

95. Peters C, Steward CG. Hematopoietic cell transplantation for inherited metabolic diseases: an overview of outcomes and practice guidelines. Bone Marrow Transplant. 2003;31:229-39.

96. Peters C, Charnas LR, Tan Y, Ziegler RS, Shapiro EG, DeFor T, et al. Cerebral X-linked adrenoleukodystrophy: the international hematopoietic cell transplantation experience from 1982 to 1999. Blood. 2004;104:881-8.

97. Sauderson NSR, Castro MG, Lowenstein PR. Chapter 29: gene therapy: from theoretical potential to clinical implementation. In: Emery and Rimoin's principles and practice of medical genetics. Philadelphia, PA: Elsevier; 2013. p. 1-32.

98. Biffi A, Capotondo A, Fasano S, del Carro U, Marchesini S, Azuma $\mathrm{H}$, et al. Gene therapy of metachromatic leukodystrophy 
reverses neurological damage and deficits in mice. J Clin Investig. 2006;116:3070-82.

99. Tse W, Laughlin MJ. Umbilical cord blood transplantation: a new alternative option. Hematology Am Soc Hematol Educ Program. 2005; 1:377-83.

100. Escolar ML, Poe MD, Provenzale JM, Richards KC, Allison J, Wood S, et al. Transplantation of umbilical-cord blood in babies with infantile Krabbe's disease. N Engl J Med. 2005;352:2069-81.

101. Staba SL, Escolar ML, Poe M, Kim Y, Martin PL, Szabolcs P, et al. Cord-blood transplants from unrelated donors in patients with Hurler's syndrome. N Engl J Med. 2004;350:1960-9.

102. Eisengart JB, Rudser KD, Tolar J, Orchard PJ, Kivisto T, Ziegler RS, et al. Enzyme replacement is associated with better cognitive outcomes after transplant in Hurler syndrome. J Pediatr Mosby Inc. 2013;162:375.e1-380.e1.

103. Mountford JC. Human embryonic stem cells: origins, characteristics and potential for regenerative therapy. Transfus Med. 2008; $18: 1-12$

104. Hanson C, Hardarson T, Ellerström C, Nordberg M, Caisander G, Rao M, et al. Transplantation of human embryonic stem cells onto a partially wounded human cornea in vitro. Acta Ophthalmol. 2013;91:127-30.

105. Wu SM, Hochedlinger K. Harnessing the potential of induced pluripotent stem cells for regenerative medicine. Nat Cell Biol Nat Publ Group. 2011;13:497-505.

106. Zou J, Mali P, Huang X, Dowey SN, Cheng L. Site-specific gene correction of a point mutation in human iPS cells derived from an adult patient with sickle cell disease. Blood. 2011;118:4599-608.

107. Ledley FD, McNamee LM, Uzdil V, Morgan IW. Why commercialization of gene therapy stalled; examining the life cycles of gene therapy technologies. Gene Ther Nat Publ Group. 2014;21:188-94.

108. Howe SJ, Mansour MR, Schwarzwaelder K, Bartholomae C, Hubank M, Kempski H, et al. Insertional mutagenesis combined with acquired somatic mutations causes leukemogenesis following gene therapy of SCID-X1 patients. J Clin Investig. 2008;118:3143-50.

109. Herzog RW. Gene therapy for SCID-X1: round 2. Mol Ther Nat Publ Group. 2010;18:1891.

110. Farinelli G, Capo V, Scaramuzza S, Aiuti A. Lentiviral vectors for the treatment of primary immunodeficiencies. J Inherit Metab Dis. 2014 [Epub ahead of print].

111. Brunetti-Pierri N, Auricchio A. Gene therapy of human inherited diseases. In: Valle D, Beaudet A, Vogelstein B, Kinzler K,
Antonarakis S, Ballabio A, et al., editors. OMMBID—online metabolic and molecular basis of inherited diseases. New York: McGraw-Hill; 2013. p. 1-52.

112. Cartier N, Hacein-Bey-Abina S, Bartholomae CC, Veres G, Schmidt M, Kutschera I, et al. Hematopoietic stem cell gene therapy with a lentiviral vector in X-linked adrenoleukodystrophy. Science. 2009;326:818-23.

113. Bainbridge JWB, Smith AJ, Barker SS, Robbie S, Henderson R, Balaggan $\mathrm{K}$, et al. Effect of gene therapy on visual function in Leber's congenital amaurosis. N Engl J Med. 2008;358:2231-9.

114. Sands MS. AAV-mediated liver-directed gene therapy. Methods Mol Biol. 2011;807:141-57.

115. Manno CS, Chew AJ, Hutchison S, Larson PJ, Herzog RW, Arruda VR, et al. AAV-mediated factor IX gene transfer to skeletal muscle in patients with severe hemophilia B. Blood. 2003;101:2963-72.

116. Gaudet D, Méthot J, Kastelein J. Gene therapy for lipoprotein lipase deficiency. Curr Opin Lipidol. 2012;23:310-20.

117. Sedivy JM, Sharp PA. Positive genetic selection for gene disruption in mammalian cells by homologous recombination. Proc Natl Acad Sci USA. 1989;86:227-31.

118. Stephan V, Wahn V, Le Deist F, Dirksen U, Broker B, MüllerFleckenstein I, et al. Atypical X-linked severe combined immunodeficiency due to possible spontaneous reversion of the genetic defect in T cells. N Engl J Med. 1996;335:1563-7.

119. Lai-Cheong JE, McGrath JA, Uitto J. Revertant mosaicism in skin: natural gene therapy. Trends Mol Med. 2011;17:140-8.

120. Porteus MH. Mammalian gene targeting with designed zinc finger nucleases. Mol Ther. 2006;13:438-46.

121. Urnov FD, Miller JC, Lee Y-L, Beausejour CM, Rock JM, Augustus S, et al. Highly efficient endogenous human gene correction using designed zinc-finger nucleases. Nature. 2005;435:646-51.

122. Pollack A. New YT. An experimental drug's bitter end-NYTimes.com [Internet]. NY Times. 2013. http://www.nytimes.com/ 2013/06/07/business/an-experimental-drugs-bitter-end.html?_r=0 Cited 14 April 2014. Accessed 25 Mar 2014.

123. Harrison W, Hernandez B. Ryan Dunne's White House petition for Duchene MD drug approval reaches 100,000 [Internet]. 2014. http://www.thedenverchannel.com/news/local-news/ryandunnes-white-house-petitionfor-duchene-md-drug-approvalreaches-100000 Cited 14 April 2014. Accessed 22 Apr 2014.

124. Dennis B. FDA relents in battle against Duchenne muscular dystrophy. Boston: Boston Globe; 2014. 